\title{
As ondas quebram em Bernard: por uma nova leitura de The Waves
}

Davi Pinho

\section{Resumo}

Ao fechar The Waves (1931) com o monólogo estendido de Bernard após uma narrativa absolutamente fragmentada pelas seis vozes que passam com seu dia simbólico, Virginia Woolf nos abre para uma nova possibilidade de leitura de sua obra prima: a de que toda sua narrativa seja sustentada por essa última seção e sua personagem central. O presente ensaio faz uma leitura de trás para frente do romance de Woolf, do momento do instante (presente) ao momento rememorado (passado), uma leitura em consonância com Bernard enquanto fio condutor da narrativa. Para fazer isso, traçamos um diálogo com o que Woolf cunhou como sua filosofia em Moments of Being (1971), sua teoria sobre os momentos de ser (being) e os de não-ser (non-being), e o tempo do instante que comprime o passado e o futuro em imagens segundo Santo Agostinho em suas Confissões. Bernard parece nos apresentar as ondas que nos vem de nós mesmos, nossas memórias e desejos, num movimento de inevitável quebra que gera o humano.

Palavras-chave: As Ondas; imagem; memória; tempo; Virginia Woolf. 
Virginia Woolf escrevia o que seria uma coleção de memoirs quando entregou-se ao rio Ouse em 1941. Em seu Moments of Being ${ }^{1}$, momentos de vida, ou de ser, a escritora não teve medo de resumir e definir sua procura pelo it que une toda a humanidade como uma filosofia, sua filosofia derradeira. ${ }^{2}$ Nossas vidas, Woolf diz, são divididas entre os momentos de ser, ou sendo (being), e os de não ser (non-being). Os momentos de não ser são aqueles destinados às atividades que nos definem enquanto seres sociais: nossos trabalhos, nossos trajetos, nossas conversas, o falatório da vida. Os momentos de ser, no entanto, são os momentos nos quais as atividades mais corriqueiras são quebradas por um silêncio que paralisa a ação, e assim nos levam a um contato com as forças por trás dos nossos movimentos corporais, como se percebêssemos algo para além dos nossos corpos e atividades isolados e adentrássemos um lugar onde a vida fala com ela mesma. Nesse lugar, no silêncio do pensamento, as barreiras aparentemente fixas que nos separariam uns dos outros, nossos sexos, nomes, nacionalidades, seriam alargadas pela vontade de ser, pelo movimento do pensar. The Waves (1931) parece pôr a filosofia de Woolf em questão antes da autora conseguir organizá-la; portanto, ao romance tornaremos com uma proposta de leitura em consonância com a filosofia derradeira de Woolf.

Os momentos de ser para Woolf são momentos de conexão, momentos em que a superfície é perfurada e que as profundezas amorfas do ser humano se desvelam. Woolf, assim, ao final de sua jornada, nos deixa sua maior afirmação das possibilidades da arte: o desdobramento do mundo na linguagem, de mostrar todos os tempos presentes no momento do ser. The Waves, seu trabalho mais experimental, viera dez anos antes de tal afirmação, em 1931, mas é aqui entendido assim: um exercício de desvelamento das conexões que formam uma vida, dos muitos em nós, das ondas que nos trazem a nós mesmos em um eterno devir.

As leituras do romance de Woolf tanto na crítica quanto nas manifestações artísticas por ele inspirado - da célebre

1 Publicado postumamente, em 1974.

2 Ver Moments of Being, 1985 [1974], p. 70-75. versão fílmica de Annete Apon, passando pela adaptação para o rádio de Terence Davies à recente peça de Katie Mitchell tentaram abarcar fisicamente todas as vozes do romance, o que não radicaliza a grande metáfora para a vida orquestrada que 
Virginia Woolf nos dá. Ou seja, em tais adaptações, todas as personagens ganharam corpo, e tentou-se remontar um certo enredo, o que se mostra na contramão do projeto artístico do romance de Woolf, pois ele parece tentar quebrar a voz isolada e o enredo linear em favor de uma polifonia simultânea. Tentar achar o desenho da narrativa, o que de representação resta na obra de Woolf, parece esquecer aquela outra temporalidade: o tempo do ser (of being), do instante. Para entendermos tal afirmativa, e para vislumbrarmos a nova leitura que cogitamos, precisamos antes apresentar o projeto do romance de Woolf.

The Waves é dividido em nove seções do mesmo dia, e a cada abertura Woolf indica a passagem do tempo, da manhã à noite. Entre as seções desse dia simbólico, estão as vidas de seis personagens, da infância à maturidade, metaforizadas pelo dia que passa. O romance de Woolf, contado a partir dessas seis vozes que se entrelaçam em seus olhares do mundo exterior, é justamente resultado da vontade de criar imagens paralelas que remetam à ideia de uma vida permeada por outras, uma vida onde outras vozes confundem o Um e o Outro, cujo jogo da alteridade cria dobras profundas e duradouras. Ou seja, Woolf nos dá seis personagens cujas vidas parecem interligadas mesmo na diferença, pois têm os mesmos referenciais - todas tomam parte do mesmo dia que começa e se vai.

É interessante que apenas ouçamos a voz de Bernard após a morte de Percival, uma sétima personagem silenciosa que só é vista através dos amigos Bernard, Neville, Louis, Jinny, Rhoda e Susan, mas que parece dar forma aos amigos, ligá-los no amor que dividem pelo mesmo, como o farol de To the Lighthouse (1927). Woolf só nos dá uma voz, uma visão, na última seção de seu romance, no cair do dia, na velhice. Bernard, nessa nona seção, parece conversar diretamente com o leitor ao tentar dar o sentido de sua vida para um companheiro de jantar silencioso, cuja figura guia o sentido da fala do personagem de Woolf. Como se nós, leitores, agora postos na posição da companhia silenciosa que janta com Bernard, fizéssemos a pergunta derradeira a ele (quem é você? por que nos fala?), o movimento da nona seção do romance é tentar entender os limites da identidade - ou seja, quem somos quando somos. É aqui que Bernard diz-se tentado a criar uma história de si, mas como ele diz, sua vida não é como uma uva, redonda, fixa, pe- 
sada, que se separa do cacho: ele é também o cacho e as outras uvas que brotam do mesmo fio, todas diferentes mas iguais. ${ }^{3}$

Nesse sentido, podemos ler o romance como os tempos presentes em Bernard, como as fases de seu dia, já que seu discurso final é paralelo às outras vozes do romance. Ou seja, podemos ler o romance a partir desse último dia, do presente, e assim, leríamos a narrativa de Woolf de trás para frente, remontando os eventos narrados. Se a nona seção toca o presente, todo o caminho do romance pode ser entendido como as memórias desse Bernard agora velho em seu monólogo final, agora entendido como um solilóquio de um moment of being.

Destarte, ele se torna a personagem central da narrativa de Woolf ao fechar o romance com uma fala que remonta todos os acontecimentos aparentemente passados, mas que ainda assim informam seu presente. Em uma releitura, se voltarmos às primeiras ondas que abrem o romance, percebemos que na verdade as imagens que permeiam o livro são todas reproduzidas por Bernard em seu discurso final. Woolf, assim, nos mostra que os tempos do romance são paralelos, e nos apresenta o tempo do humano - a memória é o passado, o desejo é o futuro, mas ambos estão no momento, no presente, na fala derradeira de Bernard. O tempo de Woolf é circular, como as ondas de seu título, e suas dobras quebram em nossas falas, no amontoado de experiências que montam a vida.

Bernard é o catalizador final das imagens do romance, aquele que narra os acontecimentos passados, mesmo que já narrados, e empreende $o$ ato final de Woolf: um novo entendimento dos tempos do ser (of being). Digo imagens em um paralelo com Santo Agostinho, pois ele diz que

quando narramos os acontecimentos passados, que são verdadeiros, nós os tiramos da memória. Mas não são fatos em si [...] e sim as palavras que exprimem as imagens que os próprios fatos, passando pelos sentidos, deixaram impressas no espírito. Minha infância, que não existe mais, está no passado, que também não mais existe. Mas a imagem dela, quando a evoco e é objeto de alguma conversa, eu a vejo no presente, porque está ainda na minha memória. Confesso-te, meu Deus, que não sei se é análogo o caso da predição do futuro, com a qual se preveem, como já existentes, as imagens das coisas que ainda não existem. [...] Quando empreender-

3 Cf. WOOLF, 1931

[2008], p. 200.

4 Meus grifos. mos e começarmos a realizar o que premeditávamos, então esse ato existirá, pois não será mais futuro, e sim presente. ${ }^{4}$ (AGOSTINHO, 2006, p. 343) 
Os sentidos agem ininterruptamente sobre os acontecimentos passados e futuros no momento da passagem da memória ou desejo para o único tempo real, o presente. Os sentidos são então filtros atualizadores de acontecimentos, o que condiciona todos os tempos ao tempo do pensamento, do ser. São os acontecimentos filtrados pelo presente, sejam eles acontecimentos rememorados ou desejados, que deixam imagens impressas no espírito. Narrar uma imagem significa registrar uma nova impressão nela e em quem a narra, um processo de diálogo entre o eu da imagem (passada ou futura) e o eu real, do instante, do presente. A infância de Santo Agostinho quando lembrada, como ele diz na citação, é uma imagem que o abre para diálogo com ele mesmo. São as palavras, então, que trazem as imagens que chamamos de passado e futuro à tona, de volta para o instante. Sendo assim,

[...] a imagem sempre volta diferente, atualizada, e novos sentidos são adensados quando ela é rememorada pela linguagem na fala. Portanto, vagarosamente, os fatos parecem se diluir em palavras perpassadas por sentimentos no presente. Até mesmo os fatos já não parecem fatos em si para o Eu na I-magem. Do latim imaginari, da mesma raiz de imitari, a imagem re-produz, nos re-produz (nos imita), e re-produz outros. Não são fatos que subtraímos das imagens, são visões. (PINHO, 2015, p. 19)

Uma leitura de The Waves através de Agostinho mostra que é Bernard quem re-produz Susan, Rhoda, Jinny, Louis, Neville e Percival ao final do romance de Woolf. Ou seja, já que todo o tempo do romance é remontado, os acontecimentos anteriores podem ser lidos como imagens que se dobram em rolos, criam ondas, e finalmente quebram no instante cabal, na vida de Bernard em seu cortejo final.

O romance é assim ressignificado por Bernard, o Eu da I-magem produzida na nona seção da narrativa de Woolf. Se voltarmos a Agostinho em suas confissões para mais uma analogia com o pensamento de Woolf, lá ele diz que o tempo humano é apenas um: o presente. As I-magens que quebram em nossa fala, como ondas na praia, são ou memórias do presente (passado) ou o desejo do presente (futuro) - não há passado que não seja memória, nem futuro que não seja desejo, o que há então é o instante, o momento do ser que Virginia Woolf 
5 Uma discussão de como entendo I-magem se dá mais extensamente na introdução de meu livro, Imagens do feminino na obra e vida de Virginia Woolf: "O Um, em algarismos romanos, ou $E u$, do inglês $I$, está na minha I-magem. Mas quando narro, e trago esse $E u-U m$ para a linguagem, o I se torna palavra, e se abre para a significação do espectador tanto quanto a sala, o raio de sol, e as árvores. $\mathrm{O} \mathrm{Um}$ vira um Outro. Uma imagem é dinâmica, nunca estática; uma perspectiva individual que não se fecha, mas ganha vida quando lida, vista, ouvida. Ela permite que o passado venha ao presente através da visão. Visão do Eu/Um, mas sobretudo do Outro, que escuta. Se guardada em mim, essa I-magem não vive, fica encerrada no tempo particular, vira uma imagem passada de um tempo passado. Mas se a narro, se a pinto, trago-a para uma dialética com o presente através do outro. Assim, a minha imagem vira uma memória do meu presente e do presente de muitos outros. Eu viro outros, e o olhar que viu parece guiar cada vez menos o sentido particular, e parece o abrir cada vez mais para significações diversas" (PINHO, 2015, p. 19).

6 Hélène Cixous tem uma famosa formulação que resume a questão de Bernard: "é por isso que eu nunca me pergunto 'quem sou eu?' (qui suis-je?) eu me pergunto 'quem são eu?' (qui sont-je?)" (1994, p. XVII) - homófono do francês qui songe?, em português quem sonha, devaneia, contempla? nos fala. ${ }^{5}$ Os enredos historicizantes que criam as ideias de passado e futuro nada mais são, segundo Santo Agostinho, que imagens de tempos imaginados no instante, no presente a impossibilidade de Bernard em responder à pergunta implícita (quem é você? por que nos fala?) que o lança ao solilóquio é justamente uma constatação de que ele é o fluxo que quebra no presente. Ou seja, é o fluxo constante de tudo que resta nele de memória (passado) e desejo (futuro), esses tempos que o ligam aos outros de sua vida, aos seus amigos, que lhe dão uma identidade eternamente atualizável. Bernard se descobre Um com os Outros, ou o Um de Outras I-magens. Como Hélène Cixous mais tarde, Bernard não tem como se perguntar quem ele é, mas quem ele são. ${ }^{6}$

Sendo assim, as primeiras palavras de Bernard na noite de sua vida, na última seção do romance, nos apontam para a impossibilidade de uma narrativa linear, já que a vida não é uma história simplesmente comunicável, uma narrativa coerente; quando ela é, ao contrário, justamente um conjunto de histórias, de experiências aglomeradas entre a memória e o desejo, o passado e o futuro. O texto de Woolf que precede a fala de Bernard apresenta sua questão na própria forma de seu romance; por sua vez, a fala de Bernard radicaliza a própria face fragmentária do texto. É ele quem aparece como um fio que une todos aqueles instantes, todos aqueles momentos de ser. É ele, na fala de si, quem desdobra o passado e o futuro no presente.

É ao tentar achar o que faz dele um indivíduo nessa grande orquestra de vozes que o compõem que Bernard, agora um escritor idoso, reconhecido, produz um discurso que delata a coerência e unidade ilusórias de histórias lineares, com início meio e fim, com a intenção de transmitir um sentido pessoal totalizado. Para ele, é apenas no silêncio da linguagem dos amantes, ou seja, naquilo que é tensionado entre o Um e o Outro, no presente, nos fragmentos remontados, que se pode achar o humano, as imagens que afirmam a vida contra aquela velha inimiga que se aproxima, a morte:

Como as crianças, nós contamos uns aos outros histórias, e para enfeitá-las, nós criamos essas frases ridículas, extravagantes e lindas. Como estou cansado de histórias, como estou cansado de frases que tocam lindamente os seus pés no chão! E mais, como eu desconfio de desenhos de vida organizados 


\begin{abstract}
que são delineados em cima de meias-folhas de papel de carta. Eu começo a ansiar por alguma pequena linguagem como a que os amantes usam, palavras quebradas, palavras inarticuladas, como o arrastar de pés no chão. Eu começo a buscar por algum desenho em mais harmonia com os momentos de humilhação e triunfo que vem agora e então inegavelmente. Deitado em uma vala em um dia de tempestade, quando tiver chovido, e então ver enormes nuvens marchando sobre o céu, nuvens esfarrapadas, fiapos de nuvem. O que me encanta é, então, a confusão, a altura, a indiferença e a fúria. Grandes nuvens sempre mudando, e o movimento; algo sulfuroso e sinistro, enroladas, apressadas; erguendo-se como torres, criando trilhas, separando-se, perdidas, e eu esquecido, minúsculo, em uma vala. De narrativa, de desenho, aí então não vejo coisa alguma.7 (WOOLF, 2008 [1931], p. 199-200)
\end{abstract}

7 Todas as traduções da obra de Woolf aqui usadas são minhas.
Bernard, como Woolf em seu ensaio "Modern Fiction" (1919), abre o romance para o tempo presente. Como nos diz Bernard acima, a linguagem dos amantes, quebrada, que se arrasta pelo chão e não o toca simples e lindamente, é uma linguagem que se deixa aberta, obscura, e aponta para as passagens dos outros em nós mesmos. Uma linguagem que não produz um argumento definitivo sobre o real, mas que o revela em todas as suas eternas possibilidades. Ela é uma linguagem que mostra outras imagens que vêm não apenas de Woolf, de Bernard, mas também de outros, e que também serão organizadas por outros. Como Bernard, não temos como narrar de forma linear o mistério da vida e as imagens dos outros que formam e informam a visão humana, o desenho espalhado que é a nossa história. Apenas ao reler os fragmentos do dia que passa remontados na fala final de Bernard, pode-se então entender quão radical o projeto de Woolf é: uma refutação da coerência dos grandes discursos que põe no indivíduo a possibilidade de um novo entendimento entre o ser e o seu mundo.

É interessante que Bernard oponha a linguagem dos amantes, erótica e obscura, à linguagem da narrativa tradicional, linear, coerente. O solilóquio, grande tradição no teatro shakespeariano, é considerado uma quebra no tempo da peça, uma invasão do tempo individual no tempo linear da narrativa, e em termos teatrais, éo tempo do solilóquio que Bernard deseja. Em sua forma novelística tão explorada pelos modernistas, no monólogo interior de Woolf, vemos a possibilidade de um 
entendimento do que Woolf chama de momento do ser, pois é na tensão entre o tempo dramático das narrativas tradicionais e o tempo do monólogo/solilóquio que o momento se apresenta.

A vida é um tecido, ${ }^{8}$ diz Woolf em seus escritos derradeiros, voltamos a seu Moments of Being para uma articulação com isso que ela chama de sua filosofia final. Se olharmos bem de perto, descobriremos os furos da costura que o compõem. Woolf nos diz ao final de sua vida que fazer arte é adentrar a costura, filtrar os choques da memória e do desejo e trazê-los para a superfície da linguagem ao deixar-se aberto às quebras das ondas e suas dobras em nós: o pensamento. Para exemplificar a distinção que faz entre being e non-being, Woolf nos dá três imagens de sua infância e elucida como tais momentos se lhe vinham. A primeira imagem é a de uma briga com seu irmão; a segunda, a dela mesma enquanto ouvia a história do suicídio de um amigo próximo da família; e a terceira é a imagem de uma flor solitária que ela vira, a imagem dela em frente à flor. Nos três momentos, cujos sentidos poderiam parecer completos em suas representações, algo no movimento da cena a fez parar e pensar nos significados velados pela aparente fixidez do que era visto.

Ao receber os primeiros socos de Thoby, um choque tomou Woolf na infância, e algo como um desdobramento de si mesma a fez parar e pensar sobre a ação de erguer as mãos e atacar um ser amado, sobre a oposição, sobre os poderes destrutivos do ser humano. Ao ouvir do suicídio de Mr. Valpy, amigo da família, ela mais uma vez recorda sentir como se houvesse se desligado do mundo exterior, e lembra-se de sair em seu ruminar até se deparar com a macieira nos derredores de sua casa. De alguma maneira, a macieira estava conectada ao horror da morte, Woolf nos diz simbolicamente: a maçã era a morte, algo em sua imagem parece intuir. Ambos os momentos a levaram a um estado de desespero na infância, de dejeção, como se os choques fossem maiores que sua capacidade de filtrá-los, de pensá-los naquele momento.

Aqui a imagem da flor difere das duas outras, Woolf nos

8 Para a discussão que segue, ver Moments of Being, p. 70-75. diz. Nos três momentos, quando estava in being, Woolf diz que a sensação que lembra é a de paralisia, como se naqueles 
momentos que ela recorda ela estivesse em um transe, como se houvesse adentrado um lugar desconhecido de si. No entanto, a flor lhe dá a possibilidade de escapar do momento, de filtrar o choque imediatamente e esperar sua digestão sem o desespero, sem o medo de que sua única realidade fosse o fim. Em um dia usual, ela lembra do último episódio de sua infância, algo na flor a leva a um momento de silêncio no qual ela parece enxergar para além da flor, como se entendesse, na profunda quebra do pensamento, que a flor era apenas parte flor, mas também parte terra, parte mundo. Tal noção, Woolf diz, se guarda dentro dela, como se a criança que havia visto a flor intuísse que um dia conseguiria traduzir seu choque para a linguagem, o que Woolf faz apenas meses antes de sua morte.

Talvez a abertura para receber os choques do ser (ofbeing), Woolf diz em uma passagem altamente poética, seja amortizada pela linguagem adulta da comunicação, da atividade, do progresso. O que lhe faz artista é sua capacidade madura de filtrar os choques, de trazê-los para a superfície da linguagem agora em sua vida adulta, e ainda assim continuar aberta às quebras nada utilitárias do pensamento, ao sendo (of being), ao movimento/ momento de ser aquilo que já se é, às ondas que se erguem e quebram, para lembrarmos de Bernard. Woolf mostra, ao final de sua vida, marcas do humano que sonhou efetivar. Nem homem nem mulher, nem criança nem adulto, o trajeto de Woolf aponta para o humano do humano, pois

\footnotetext{
por trás da lã de algodão está escondido um padrão; que nós - quero dizer todos os seres humanos - estamos ligados a ele; que o mundo inteiro é uma obra de arte; que somos partes da obra de arte. Hamlet ou um quarteto de Beethoven é a verdade sobre esta vasta massa que chamamos de mundo. Mas não há Shakespeare, não há Beethoven; certamente e enfaticamente não há Deus; somos as palavras; somos a música; nós somos a própria coisa. (WOOLF, 1974, p. 72)
}

É o pensamento aquilo que nos permite enxergar por entre os pontos infinitesimais que compõe a aparente estabilidade do tecido humano, a lã de algodão que é a vida, para além das representações que forjam a trama. É o pensamento aquilo que nos permite perfurar a trama, a narrativa, o desenho. As 
ondas que vêm no título do romance de Woolf podem ser lidas como os momentos de ser de suas personagens, momentos esses que se tornam todos de Bernard quando ele os recebe em choques na nona seção do romance, quando enfim a trama é perfurada pelo largo pensar do monólogo de Bernard, pelo movimento de se entender humano. São os momentos de ser, de vida, aquilo que dá a Bernard um certo entendimento do ininteligível, de que ele é constituído por conexões para além de suas representações linguísticas. Ou seja, como Orlando, ${ }^{9}$ outra grande personagem de sua obra, Bernard se descobre poeticamente muitos e um só.

Pensar essa nova leitura de The Waves, pensar o monólogo-vida de Bernard como um último fio condutor dos tempos fragmentados no dia que passa, ou melhor, como um último catalizador dos amigos que se tornam imagens, pode levar a obra de arte de Woolf a um outro grau de realização. Tal leitura leva a arte posta em obra por Woolf à plenitude ainda hoje em dia, pois permite que o discurso de Bernard ecoe, ou ressoe, através dos nossos eternos momentos de vida (of being), pois podemos nós agora tê-lo como imagem catalizadora de nós mesmos, tal qual a ele estavam abertas as imagens de Jinny, Rhoda, Susan, Neville, Louis e até mesmo a do silencioso Percival.

O percurso de Woolf entre The Waves e suas memórias, seu Moments of Being, aparece em si como o movimento de uma de suas ondas. De um entendimento poético a uma ilustração filosófica, Woolf parece nos dizer que o movimento da onda é o do ser humano em sua permanente pergunta até que enfim a onda chegue à praia - quem vem? Por que precisa a onda quebrar em mim? Qual das imagens em mim remete ao Eu da I-magem? O que resta de mim em meu nome, em meu sexo, em meu país? Quem, enfim, sou eu quando sou?

Mas agora deixe-me perguntar a mim mesmo a pergunta final, enquanto eu me sento sobre este fogo cinza, com seus promontórios nus de carvão preto, qual dessas pessoas sou

9 Personagem título de eu? Depende tanto do cômodo. Quando eu digo para mim Orlando (1928). mesmo “Bernard", quem vem? (WOOLF, 1931, p. 65) 


\title{
REFERÊNCIAS
}

AGOSTINHO, Santo. Confissões. São Paulo: Paulus, 2006.

CIXOUS, Hélène. Preface. In: SELLERS, Susan (Org.). The Hélène Cixous Reader. London: Routledge, p.XV-XXIV, 1994.

PINHO, Davi. Imagens do feminino na obra e vida de Virginia Woolf. Porto Alegre: Editora Appris, 2015.

WOOLF, Virginia. Moments of Being. London: Harcourt Brace and Company, 1985. [1974] . The Waves. London: Oxford World Classics, 2008.

[1931]

\begin{abstract}
Waves breaking on Bernard: Towards a New Reading of The Waves

By closing The Waves (1931) with Bernard's extended monologue after presenting a narrative absolutely fragmented by the six voices that pass along with her symbolic day, Virginia Woolfopens us to a new possibility of reading her masterpiece: that of understanding her entire narrative as sustained by its last section and its central character. This essay proposes a backwards reading of Woolf's novel, from the time of the instant (present) to recollected time (past), a reading in accordance with Bernard as the binding thread of her narrative. To do this, we draw a parallel with what Woolf coined as her philosophy in Moments of Being (1941, 1971), her theory about moments of being and of non-being, and the time of the instant, which compresses both past and future into images according to St Augustine in his Confessions. Bernard seems to present us with the waves that come to us from ourselves, our memories and desires, in a movement of inevitable break that begets the human.
\end{abstract}

Keywords: The Waves; image; memory; time; Virginia Woolf. 